\title{
A structural analysis of working memory and related cognitive skills in young children
}

\author{
Tracy Packiam Alloway, ${ }^{\mathrm{a}, *}$ Susan E. Gathercole, ${ }^{\mathrm{a}}$ \\ Catherine Willis, ${ }^{\mathrm{b}}$ and Anne-Marie Adams ${ }^{\mathrm{b}}$ \\ a Department of Psychology, University of Durham, Science Laboratories, South Road, \\ Durham DH1 3LE, UK \\ b John Moores University, Liverpool, UK
}

Received 27 June 2003; revised 3 October 2003

\begin{abstract}
The aim of this study was to investigate the functional organisation of working memory and related cognitive abilities in young children. A sample of 633 children aged between 4 and 6 years were tested on measures of verbal short-term memory, complex memory span, sentence repetition, phonological awareness, and nonverbal ability. The measurement model that provided the best fit of the data incorporates constructs that correspond to the central executive, phonological loop, and episodic buffer subcomponents of working memory, plus distinct but associated constructs associated with phonological awareness and nonverbal ability.
\end{abstract} (c) 2003 Elsevier Inc. All rights reserved.

Keywords: Working memory; Central executive; Phonological loop; Episodic buffer; Phonological awareness

\section{Introduction}

Children's abilities to store and manipulate information in short-term memory are closely associated with scholastic attainments over the school years. Links have been found between these working memory abilities and attainments in the areas of reading (e.g., De Jong, 1998; Swanson, 1994), mathematics (e.g., Bull \& Scerif, 2001;

\footnotetext{
${ }^{*}$ Corresponding author. Fax: +44-191-334-3241.

E-mail address: t.p.alloway@durham.ac.uk (T.P. Alloway).
} 
Mayringer \& Wimmer, 2000; Siegal \& Ryan, 1989), and language comprehension (e.g., Nation, Adams, Bowyer-Crane, \& Snowling, 1999; Seigneuric, Ehrlich, Oakhill, \& Yuill, 2000). Measures of working memory at school entry (at 4 or 5 years, in the UK) have also been found to provide excellent predictors of children's success in national assessments of scholastic abilities up to 3 years later (Gathercole, Brown, \& Pickering, 2003).

Interpretation of the strong associations between working memory and learning abilities requires a sound theoretical understanding of the cognitive systems underlying the working memory measures at the point at which children enter formal education and start acquiring and developing their scholastic abilities. The aim of the present study was to provide a detailed assessment of the functional organisation of working memory and other cognitive processes known also to be related to academic success, in children in their first year of compulsory full-time education.

The research was guided by the model of working memory developed originally by Baddeley and Hitch (1974), and extended by Baddeley (2000). The model consists of a central executive linked directly with three other subsystems: the phonological loop, the visuospatial sketchpad, and the episodic buffer. The central executive is a flexible system responsible for the control and regulation of cognitive processes including temporary activation of long-term memory (Baddeley, 1998), coordination of multiple tasks (e.g., Baddeley, Della Sala, Gray, Papagno, \& Spinnler, 1997), shifting between tasks or retrieval strategies (Baddeley, 1996), and selective attention and inhibition (Baddeley, Emslie, Kolodny, \& Duncan, 1998a). Additional processes including updating and shifting have also been identified (Miyake, Emerson, \& Friedman, 2000). Other theoretical accounts of general working memory that correspond in some respects to the central executive include the notions of a limited resource that can be flexibly allocated to support either processing or storage (e.g., Daneman \& Carpenter, 1980; Just \& Carpenter, 1992), and of a limited attentional resource responsible for the temporary activation of information from long-term memory (e.g., Cowan, 1988, 1995; Engle, Kane, \& Tuholski, 1999a).

Individual differences in the capacity of the central executive are commonly assessed using complex memory paradigms requiring simultaneous storage and processing of information. An example of such a task is reading span, in which the participant judges the semantic properties of sentences while remembering the last word of each sentence in sequence (Daneman \& Carpenter, 1980, 1983). According to a recent proposal, verbal complex memory tasks such as these may also rely on the verbal storage component of working memory, the phonological loop (Baddeley \& Logie, 1999; Duff \& Logie, 2001). Complex working memory span measures are effective predictors of performance in many complex cognitive activities including language comprehension (MacDonald, Just, \& Carpenter, 1992), reasoning (Kyllonen \& Christal, 1990), and language and reading abilities (De Jong, 1998; Swanson, 1994).

In the working memory model, the central executive is supplemented by two slave systems specialised for temporary storage and manipulation of material in specific domains. The verbal storage system is the phonological loop, composed of a short-term phonological store subject to rapid decay plus a subvocal rehearsal pro- 
cess that can be used to restore decaying representations within the store (Baddeley, 1986). Theoretical accounts of memory other than the working memory model also incorporate verbal storage-only short-term memory systems that are distinct from the more flexible capacities of working memory (e.g., Cowan, 1997; Engle, Tuholski, Laughlin, \& Conway, 1999b). The capacity of the phonological loop is typically assessed by serial recall tasks involving arbitrary verbal elements such as digits and words. The phonological loop has been suggested to play a key role in the acquisition of vocabulary, particularly in the early childhood years (Baddeley, Gathercole, \& Papagno, 1998b).

The second slave system in the working memory model is the visuospatial sketchpad, specialised for the processing and maintenance of material that can be represented in terms of its visual or spatial characteristics (e.g., Baddeley \& Lieberman, 1980; Della Sala, Gray, Baddeley, Allamano, \& Wilson, 1999). The final component of working memory is the episodic buffer, fractionated from the central executive in the most recent revision of the model (Baddeley, 2000). The episodic buffer uses multidimensional codes to integrate representations from components of working memory and long-term memory into unitary episodic representations that may correspond to conscious experience. In the revised model the episodic buffer provides direct inputs into episodic long-term memory, raising the possibility that this component of working memory too may provide an important gateway for learning.

One cognitive skill that is also closely associated with both short-term memory and children's abilities to acquire language skills including literacy is phonological awareness - the ability to encode, access, and manipulate the sound units of language. Phonological awareness can operate at a number of different levels and has a clear developmental function that proceeds from relatively large phonological units such as syllables in the preschool period through to finer-grained analysis at the level of individual phonemes typically achieved in the middle school years (e.g., Goswami \& Bryant, 1990; Morais, Content, Bertelson, Cary, \& Kolinksy, 1988). Tests of phonological awareness vary considerably in terms of both the size of the phonological units to be manipulated and the degree of explicit metalinguistic awareness they require. Examples include judgments of rhyme (e.g., Bradley \& Bryant, 1983), blending phonological elements (Mann \& Liberman, 1984), deletion of phonological segments (e.g., Treiman \& Baron, 1981), phoneme and syllable counting (e.g., Liberman, Shankweiler, Liberman, Fowler, \& Fischer, 1977), judgments of shared phonemes in sequences of words (Kirtley, Bryant, MacLean, \& Bradley, 1989), and spoonerizing pairs of verbal stimuli (Perin, 1983). Proficiency in phonological awareness tasks is highly associated with reading ability (e.g., Bradley \& Bryant, 1985; Goswami \& Bryant, 1990; Wagner \& Torgesen, 1987), and has also been linked with vocabulary learning abilities (De Jong, Seveke, \& van Veen, 2000; Metsala, 1999).

Measures of verbal short-term memory and phonological awareness are strongly associated (Siegal \& Linder, 1984; Stanovich, Cunningham, \& Freeman, 1984), and a variety of explanations for this relation have been advanced. According to one view, phonological memory and awareness measures tap a common phonological coding or processing substrate (e.g., Bowey, 1996; De Jong et al., 2000; Dufva, Niemi, \& Voeten, 2001; Garlock, Walley, \& Metsala, 2001; Griffiths \& Snowling, 2002; 
Metsala, 1999). This view receives some support from findings from a large cohort of 5 -year-old children demonstrating that a single latent construct accounted for individual differences for working memory span tasks and phonological analysis tasks (Wagner, Torgesen, Laughon, Simmons, \& Rashotte, 1993; see also Wagner et al., 1987). A second view is that verbal short-term memory tasks provide more direct indices of the quality of underlying phonological representations, whereas phonological awareness tasks rely on a more general metalinguistic awareness of the phonological forms of words (Windfuhr \& Snowling, 2001). This position is consistent with evidence of a degree of independence in the links between the two phonological skills and reading ability (e.g., Hulme \& Snowling, 1992; Wagner, Torgesen, \& Rashotte, 1994). A third account is that verbal short-term memory and phonological awareness tasks are constrained by the adequacy of phonological processes, but that they also tap distinct mechanisms involving the phonological loop and metalinguistic analysis, respectively (e.g., Gathercole, Willis, \& Baddeley, 1991; Hecht, Torgesen, Wagner, \& Rashotte, 2001; Muter \& Snowling, 1998).

One reason why the close associations between phonological short-term memory and phonological awareness tasks are difficult to interpret is that many tasks devised to tap phonological awareness also impose significant burdens on verbal memory. For example in tasks such as sound categorisation (e.g., Oakhill \& Kyle, 2000) and phoneme deletion (e.g., Leather \& Henry, 1994), one or more phonological representations must be stored while further analytic procedures such as comparison and deletion of segments are being carried out. Correlations between phonological memory and awareness measures may therefore reflect the relative impurity of tasks rather than common underlying constructs.

A further cognitive skill that is linked with children's capacities to acquire knowledge and skills in the early school years is nonverbal ability. Measures of nonverbal ability are widely interpreted as reflecting general fluid intelligence and are good predictors of indices of learning ability such as reading achievement (e.g., Stanovich et al., 1984). Previous studies indicate that nonverbal ability is distinct from, although highly correlated with, measures of complex memory span associated with the central executive (e.g., Conway, Cowan, Bunting, Therriault, \& Minkoff, 2002; Engle et al., 1999b).

The aim of the present study was to identify the functional organisation of cognitive measures that have been linked with children's abilities to acquire knowledge and skills over the early school years. More than 600 children aged 4 to 6 years were tested on measures associated with the four components of working memory (central executive, phonological loop, episodic buffer), phonological awareness, and nonverbal ability. Children were tested in their first year of school (ages 4 to 6 years) as this point in time provides the platform for scholastic learning and progress. On the basis of recent evidence that the adult model of working memory is in place as early as 6 years of age (Gathercole, Pickering, Ambridge, \& Wearing, in press), the structure of working memory in this young age group was not expected to differ markedly from that of older children and adults.

The following measures of each construct were employed in the study. Three complex memory span tasks involving concurrent processing and storage demands were 
chosen to tap the central executive: backwards digit recall and counting recall (Pickering \& Gathercole, 2001), and sentence completion and recall (Towse, Hitch, \& Hutton, 1998). Three measures of the phonological loop were selected: digit recall and word recall (Pickering \& Gathercole, 2001) and nonword repetition (Gathercole \& Baddeley, 1996).

As this is the first study to our knowledge that has attempted to investigate the episodic buffer in children, it was necessary to develop a method for its assessment. The paradigm we chose was recall of spoken sentences. Repeating sentences involves the integration of information from temporary memory subsystems (to support the verbatim recall of individual words and their order) with the products of semantic and syntactic analysis by the language processing system. The integration of these two sources of representation is demonstrated by the superiority in memory span for words in meaningful sentences than in unrelated word lists (e.g., Baddeley, 1986; Potter \& Lombardi, 1990). In neuropsychological patients with selective impairments corresponding to the phonological loop, sentence span exceeds that of word span but is nonetheless impaired (Martin, Lesch, \& Bartha, 1999; McCarthy \& Warrington, 1987; Vallar \& Baddeley, 1984). Baddeley (2000) explained these findings in terms of the use of the episodic buffer to mesh representations of the sentence from the phonological loop and from the language processing system. Sentence repetition therefore provides a reasonable initial assessment of the capacity of the episodic buffer. A further important feature of the task is that it is appropriate for use with children as young as 4 years (Willis \& Gathercole, 2000). To provide a relatively broad-based assessment of sentence repetition ability, two separate sentence repetition tests were developed. The test differed in sentence type: in one, the sentences shared a simple active structure, whereas sentences in the other test incorporated syntactic structures that varied in complexity.

Phonological awareness was assessed using two sound categorisation tasks appropriate for the age group, one involving the detection of rhyme (Muter, Hulme, \& Snowling, 1997) and the other requiring detection of initial consonants (Byrne \& Fielding-Barnsley, 1993). In both tasks the child was presented with line drawings corresponding to familiar words in the course of the task rather than spoken presentation of the word forms only, to minimize the short-term memory burdens of the tasks. Nonverbal ability was tested using the block design and object assembly subtests of the Wechsler Preschool and Primary Scale of Intelligence-Revised (Wechsler, 1990).

As multiple assessments of each cognitive component were obtained for a large sample of children in this study, it was possible to use confirmatory factor analysis to test a variety of alternative theoretical accounts of the underlying cognitive systems. The models to be tested ranged in complexity from simple to increasingly complex and differentiated cognitive structures, based on existing theoretical positions. The simplest model tested the claim that individual differences in the range of short-term memory measures taken in the study reflect a single underlying factor. This position is supported by evidence that many age-related changes in short-term memory function can be explained in terms of changes in processing speed, rather than developmental changes in separate memory systems per se (e.g., Kail, 2002; 
Kail \& Hall, 2001; Kail \& Park, 1994). In contrast, in the model based on the Baddeley (2000) working memory position, performance on the memory measures is supported by separate factors corresponding to the central executive, phonological loop, and episodic buffer. Further models assessed the extent to which the measures of phonological short-term memory, phonological awareness, and sentence repetition tapped distinct constructs.

\section{Method}

\section{Participants}

Children from 26 state primary schools, 13 from the northwest England and 13 from northeast England, participated in this study. Parental consent was obtained for each child participating in the study. Schools were selected on the basis of the national average of eligibility for free school meals in the year 2001 (17.6\%), a poverty (income) index used in England, and represented a range of low (7-13\%), middle (15-25\%), and high (34-45\%) free school meal rates in each Local Educational Authority. A total of 633 children participated in this study, with a mean chronological age of 59.5 months $(S D=3.7$, range $=51-68$ months $)$. All participating children commenced full-time attendance at reception classes in September 2001. Information was provided by each child's principal caregiver about maternal educational level (i.e., GCSEs, A levels, vocational training or higher education) and the age at which the mother left school.

\section{Procedure}

Each child was tested individually in a quiet area of the school for three sessions lasting up to $30 \mathrm{~min}$ per session across 2 weeks. The following tests were administered, in a fixed sequence designed to vary task demands across successive tests.

\section{Complex memory span}

The backwards digit recall test of the Working Memory Test Battery for Children (WMTB-C, Pickering \& Gathercole, 2001) was administered to each child. On each trial, the child is required to recall a sequence of spoken digits in the reverse order. Test trials begin with two numbers, and increase by one number in each level, until the child is unable to recall four correct trials at a level. Test-retest reliability on the test for children aged between 5 and 8 years is .53 .

The counting recall test was also taken from the WMTB-C. In this test, the child is required to count the number of dots in an array, and then recall the tallies of dots in the arrays that were presented. A display booklet is placed in front of the child, consisting of pages displaying three, four, five, or six red dots in a box. The test trial begins with one page of a dot array, and increases by one page in each level, until the child is unable to correctly recall four trials. The number of correct trials was scored 
for each child. Test-retest reliability is .74 for counting recall, for children aged 5 to 8 years.

The third complex span measure was the sentence completion and recall task, adapted from Towse et al. (1998). In this test, the child listens to a series of short sentences with a missing word at the end, produces a word to complete the sentence, and recalls the word she or he produced for each sentence in sequence. Test trials begin with one sentence, and continue with additional sentences in each level until the child is unable to recall three correct trials at a level. The number of correct trials was scored for each child. The test-retest reliability for this task was established with 105 of the children in this study randomly selected across schools. A period of 4 weeks separated the two successive testing administrations. Test-retest reliability at 5 to 8 years is .52 .

\section{Phonological short-term memory}

The digit recall test and the word recall test of the WMTB-C (Pickering \& Gathercole, 2001) were administered to each child. In each case, the child is required to recall a sequence of digits or words in the order that they were presented. Each level in these tests begins with one digit or word and continues until the child is unable to recall four trials of the digits or words in the correct serial position. The number of correct trials was scored for each child. The Children's Test of Nonword Repetition (Gathercole \& Baddeley, 1996) provided the third assessment of the phonological loop. In this, the child is required to repeat each nonword accurately immediately after it has been presented. The test consists of 40 items, and the number of correct repetition attempts is scored for each child. Test-retest reliability coefficients are .81 for digit recall, .80 for word recall, and .77 for nonword recall. In all the working memory tasks, the children receive one point for each correctly recalled trial, and the points are summed to produce a total score for each task.

\section{Sentence repetition}

Two sentence repetition tasks were administered to each child. Both tests consisted of 10 sentences with vocabulary appropriate for the age group. Set 1 consisted of 10 sentences with simple active grammatical structures (e.g., The cup is in the box) used by Potter and Lombardi in a study of children aged 4 to 5 years (1990, Experiment 7). Set 2 consisted of 10 sentences from the Test for the Reception of Grammar (Bishop, 1982), a test of language comprehension suitable for children aged 4 to 9 years. Each sentence shared a different grammatical structure, with active and passive voices and embedded clauses modifying either the subject (e.g., The boy chasing the horse is fat) or the object (e.g., The boy rode a horse at the zoo). The sentences ranged between 6 and 9 words in length, with mean lengths of 7.9 words in Set 1 and 6.8 words in Set 2.

The experimenter spoke each sentence aloud and the child was required to recall the sentence immediately. Responses were recorded onto an audio cassette, and the 
recordings were subsequently used as the basis for scoring the accuracy of the repetition attempts. The repetition attempts were scored either as correct (all words correctly recalled in their original position in the sentence) or as incorrect, giving a maximum possible score of 10 for each of the two sets. Test-retest reliabilities were calculated for a subset of 105 children participating in the study. For Set 1, $r(103)=.67$; for Set $2, r(103)=.69$.

\section{Phonological awareness}

Two measures of phonological awareness were administered. The rhyme detection task from the Phonological Abilities Test (Muter et al., 1997) involves the child viewing a picture card with a target picture and three possible picture matches. The child is required to match the target with a picture that shares the same rhyme pattern. For example, the target picture house was presented with the following possible picture matches: mouse, horse, and window. The number of correct trials is scored for each child. Test-retest reliability on this test is .87. In the initial consonant detection task (Byrne \& Fielding-Barnsley, 1993), the child is required to match a target picture with one of two possible picture matches that share the same initial consonant. For example, the target picture goat was presented with the following possible picture matches: girl and duck. The number of correct responses is scored for each child. Test-retest reliability for this measure was established with 105 children participating in the present study: $r=.65$.

\section{Nonverbal ability measures}

Two performance subtests from the Wechsler Preschool and Primary Scale of Intelligence-Revised (Wechsler, 1990) were administered: the block design task and the object assembly task. In the first task, the child views a pattern of red and white blocks and is required to imitate the pattern in a given time limit. In the second task, the child is required to construct a specified object with a set of jigsaw pieces in a given time limit. Test-retest reliability coefficients for ages 4 to 6 years range between .56 and .70 for block design and between .84 and .87 for object assembly.

\section{Results}

\section{Descriptive statistics and correlational analyses}

The data were screened for univariate and multivariate outliers. Univariate outliers were defined as cases more than $3 S D$ above or below the mean. The data for 27 children who met this criterion on one or more measures were eliminated. Two multivariate outliers were identified and eliminated on the basis of Mahanalobis $d^{2}$ scores with $p<.001$. The final dataset for subsequent analyses consisted of 604 children. 
Descriptive statistics for the working memory measures, sentence recall, phonological awareness, and nonverbal tasks are provided in Table 1. Skewness and kurtosis values for all measures indicated normal distributions of scores.

The correlation coefficients between all principal measures are shown in the lower triangle of Table 2. Partial correlations with the general factors of age, months in school, maternal age at leaving school, and maternal education level partialed out are shown in the upper triangle. None of the general factors was strongly correlated with any of the cognitive measures (maximum $r=.21$ ).

Measures within each area of cognitive function shared correlations in the moderate to high range with $r$ s ranging from .33 to .55 , and were significant at $p<.001$ in each case. Correlation coefficients for the complex memory span measures ranged from .43 (backwards digit recall and sentence completion and recall) to .45 (backwards digit recall and counting recall). For the phonological loop measures, coefficients ranged from .37 (digit recall and nonword repetition) to .55 (digit recall and word recall). Correlations between the two sentence repetition tasks associated with the episodic buffer were high $(r=.53)$; correlations between the component phonological awareness and nonverbal measures were relatively lower although highly significant ( $r=.33$ and $r=.43$, respectively). In the partial correlation coefficients with variance associated with external factors eliminated, interrcorrelations within each area of cognitive function remained modest to high, ranging from .30 (rhyme detection and initial consonant detection) to .55 (digit recall and word recall).

Table 1

Descriptive statistics of raw scores for the working memory, phonological awareness, and nonverbal measures

\begin{tabular}{|c|c|c|c|c|c|}
\hline Variable & Mean & $\mathrm{SD}$ & $\begin{array}{l}\text { Range } \\
(\min -\max )\end{array}$ & Skewness & Kurtosis \\
\hline \multicolumn{6}{|l|}{ Central executive } \\
\hline Backwards digit recall & 4.53 & 3.02 & $0-13$ & -0.08 & -0.73 \\
\hline Counting recall & 8.47 & 2.89 & $0-17$ & 0.44 & -0.08 \\
\hline $\begin{array}{l}\text { Sentence completion } \\
\text { and recall }\end{array}$ & 11.16 & 4.66 & $0-24$ & 0.83 & 0.09 \\
\hline \multicolumn{6}{|l|}{ Phonological loop } \\
\hline Digit recall & 22.51 & 4.22 & $9-36$ & 0.08 & -0.13 \\
\hline Word recall & 15.94 & 3.32 & $6-26$ & 0.29 & 0.34 \\
\hline Nonword repetition & 17.66 & 6.54 & $2-35$ & 0.21 & -0.37 \\
\hline \multicolumn{6}{|l|}{ Episodic buffer } \\
\hline Sentence repetition: Set 1 & 6.71 & 2.24 & $0-10$ & -0.63 & -0.18 \\
\hline Sentence repetition: Set 2 & 7.53 & 1.62 & $2-10$ & -1.02 & 0.83 \\
\hline \multicolumn{6}{|l|}{ Phonological awareness } \\
\hline Rhyme detection task & 6.56 & 2.73 & $0-10$ & -0.34 & -1.12 \\
\hline Initial consonant detection & 7.90 & 2.05 & $2-10$ & -0.77 & -0.40 \\
\hline \multicolumn{6}{|l|}{ Nonverbal abilities } \\
\hline Block design & 18.97 & 6.35 & $0-37$ & -0.12 & -0.28 \\
\hline Object assembly & 21.97 & 4.93 & $7-32$ & -0.47 & -0.18 \\
\hline
\end{tabular}


Table 2

Correlations among the external factors, working memory, phonological awareness, and nonverbal abilities $(N=633)$

\begin{tabular}{|c|c|c|c|c|c|c|c|c|c|c|c|c|c|c|c|c|}
\hline Measure & 1 & 2 & 3 & 4 & 5 & 6 & 7 & 8 & 9 & 10 & 11 & 12 & 13 & 14 & 15 & 16 \\
\hline 1. Age of child & - & & & & & & & & & & & & & & & \\
\hline 2. Months at school & .290 & - & & & & & & & & & & & & & & \\
\hline 3. Age mother left school & .073 & .025 & - & & & & & & & & & & & & & \\
\hline 4. Maternal educational level & .057 & .058 & .496 & - & & & & & & & & & & & & \\
\hline 5. Backwards digit recall & .136 & .099 & .107 & .136 & - & .412 & .410 & .375 & .305 & .269 & .310 & .294 & .289 & .383 & .351 & .171 \\
\hline 6. Counting recall & .196 & .104 & .092 & .149 & .451 & - & .400 & .303 & .150 & .249 & .281 & .263 & .306 & .265 & .396 & .199 \\
\hline 7. Sentence com & .196 & .032 & .097 & .097 & .425 & .437 & - & .237 & .168 & .210 & .263 & .268 & .228 & .276 & .316 & .135 \\
\hline 8. Digit recall & .055 & .045 & .069 & .158 & .351 & .289 & .223 & - & .552 & .371 & .388 & .385 & .264 & .260 & .234 & .081 \\
\hline 9. Word recall & .057 & .091 & .064 & .074 & .299 & .145 & .162 & .552 & - & .378 & .358 & .280 & .224 & .200 & .055 & .015 \\
\hline 10. Nonw & .091 & .029 & .035 & .078 & .292 & .278 & .246 & .374 & .372 & - & .440 & .379 & .168 & .247 & .145 & .031 \\
\hline 11. Sentence repetition: Set 1 & .104 & .075 & .085 & .131 & .337 & .332 & .291 & .387 & .362 & .465 & - & .496 & .250 & .236 & .183 & .128 \\
\hline 12. Sentence repetition: Set 2 & .136 & .040 & .113 & .187 & .315 & .305 & .298 & .381 & .291 & .395 & .531 & - & .275 & .305 & .167 & .040 \\
\hline 13. Rhyme detection task & .047 & .001 & .157 & .128 & .332 & .320 & .248 & .262 & .229 & .192 & .265 & .292 & - & .295 & .198 & .157 \\
\hline 14. Initial consonant detection & .126 & .043 & .133 & .159 & .435 & .326 & .306 & .244 & .207 & .263 & .279 & .334 & .328 & - & .176 & .094 \\
\hline 15. Block design & .210 & .118 & .144 & .164 & .399 & .443 & .360 & .228 & .075 & .199 & .248 & .215 & .220 & .248 & - & .391 \\
\hline 16. Object assembly & .113 & .038 & .114 & .157 & .209 & .224 & .175 & .098 & .067 & .079 & .172 & .114 & .186 & .156 & .431 & - \\
\hline
\end{tabular}

Note. Simple correlation coefficients are shown in lower triangle; correlation coefficients with external factors (measures 1 to 4 ) partialed out are shown in upper triangle. For coefficients greater than $.084, p<.05$; for coefficients greater than $.103, p<.01$. 


\section{Exploratory factor analysis}

To investigate the higher-order factor structure underpinning variations between the different measures, a principal components analysis was conducted on the raw scores for all 11 measures, rotated to final solution with a Varimax rotation. Two factors emerged with eigenvalues in excess of 1.00, accounting for 24.51 and $23.14 \%$ of the variance, respectively. Factor loadings in excess of .30 on the rotated factor matrix are displayed in Table 3 . The five measures that loaded most highly on Factor 1 were the three phonological short-term memory measures and the two sentence repetition tasks. Lower loadings on this factor were obtained for the two phonological awareness measures (rhyme detection and initial consonant detection) and backwards digit recall. The highest loading measures on Factor 2 were the three complex memory tasks and the two nonverbal ability measures. Weaker loadings were obtained for the two phonological awareness measures. Thus the first factor appears to tap the short-term storage and retrieval of verbal information, whereas the second factor corresponds to a more general cognitive construct associated with manipulating information in both verbal and nonverbal domains. Phonological awareness measures were linked to both factors.

\section{Confirmatory factor analyses}

The next step was to evaluate the factor structure of more specific models of the data using confirmatory factor analysis (Bentler, 2001; Bentler \& Wu, 1995). This method provides a means of testing the adequacy of competing theoretical accounts of the relationships between measures, with each model specified in terms of paths between observed variables and latent constructs and between constructs. Goodness of fit is tested for each model. A commonly used index of fit is the $\chi^{2}$ statistic, which compares the degree to which the predicted covariances in the model differ from the observed covariances. Small and nonsignificant $\chi^{2}$ values indicate good fit. Because this statistic is sensitive to variances in sample sizes, with very large samples as in the

Table 3

Factor loadings $>.30$ from principal components analysis

\begin{tabular}{lll}
\hline Measure & Factor 1 & Factor 2 \\
\hline Backwards digit recall & .39 & .61 \\
Counting recall & & .68 \\
Sentence completion and recall & .73 & .61 \\
Digit recall & .75 & \\
Word recall & .68 & \\
Nonword repetition & .67 & \\
Sentence repetition: Set 1 & .64 & .43 \\
Sentence repetition: Set 2 & .33 & .47 \\
Rhyme detection task & .36 & .77 \\
Initial consonant detection & & .61 \\
Block design & & \\
Object assembly & & \\
\hline
\end{tabular}


present study even the best-fitting models frequently yield significant $\chi^{2}$ values (Kline, 1998). Following Jaccard and Wan (1996) and Kline (1998), model adequacy was therefore evaluated using additional global fit indices that are more sensitive to model specification than to sample size. The Comparative Fit Index (CFI; Bentler, 1990) and the Bollen Fit Index (IBI; Bollen, 1989) provide a further measure of fit computed by comparing the hypothesised model against a null model in which the relations between the latent variables are not specified and consequently are set at zero. An additional goodness-of-fit index that adjusts for the complexity of the model is the Normed Fit Index (NFI; Bentler \& Bonett, 1980). Fit indices with values equal to or higher than .90 demonstrate a good fit. Further assessment of the extent to which the specified model approximates to the true model is the root mean square error of approximation (RMSEA). A RMSEA value of .08 or lower is acceptable, and a value below .05 indicates a good fit (McDonald \& Ho, 2002).

In the series of models tested below, paths between latent constructs were left free to covary (represented diagrammatically as bidirectional links) in the absence of justifiable assumptions concerning direction of causality. Such models are known as measurement models. In each case, the level of significance of the path weights between each observed variable and its associated factor, and the correlations between all pairs of factors, was set at an $\alpha$ level of .05. Statistical comparison of models was achieved by performing $\chi^{2}$ difference tests (McDonald \& Ho, 2002). The statistics and fit indices generated by each of the measurement models are summarized in Table 4 . To identify the best-fitting model, a series of $\chi^{2}$ difference tests were performed and are reported following the presentation of the different model solutions.

\section{Model 1}

The first analysis tested a model based on the outcomes of the exploratory factor analysis. Model 1 consisted of two factors. The first factor was associated with all three phonological short-term memory measures, the two sentence repetition tasks, the two phonological awareness measures, and backwards digit recall. Factor 2 was associated with the three complex span tasks, the two nonverbal ability measures, and the two phonological awareness tasks. The model solution is summarised in Fig. 1, and the fit statistics are shown in Table 4. This two-factor model described above provides a tolerable fit to the data, although the $\chi^{2}$ value is very high. The weakness of the model is that it was generated in a post hoc manner, and does not provide a coherent theoretical account of the data. In particular, the loadings

Table 4

Goodness-of-fit statistics for the different measurement models

\begin{tabular}{llllllll}
\hline Model & $\chi^{2}$ & $d f$ & $p$ & CFI & IFI & NFI & RMSEA \\
\hline 1 & 224.85 & 50 & $<.001$ & .95 & .97 & .88 & .08 \\
2 & 365.13 & 51 & $<.001$ & .83 & .83 & .81 & .10 \\
3 & 117.42 & 44 & $<.001$ & .96 & .96 & .94 & .05 \\
$4 \mathrm{a}$ & 152.46 & 46 & $<.001$ & .94 & .94 & .92 & .06 \\
$4 \mathrm{~b}$ & 129.8 & 46 & $<.001$ & .96 & .96 & .93 & .06 \\
\hline
\end{tabular}




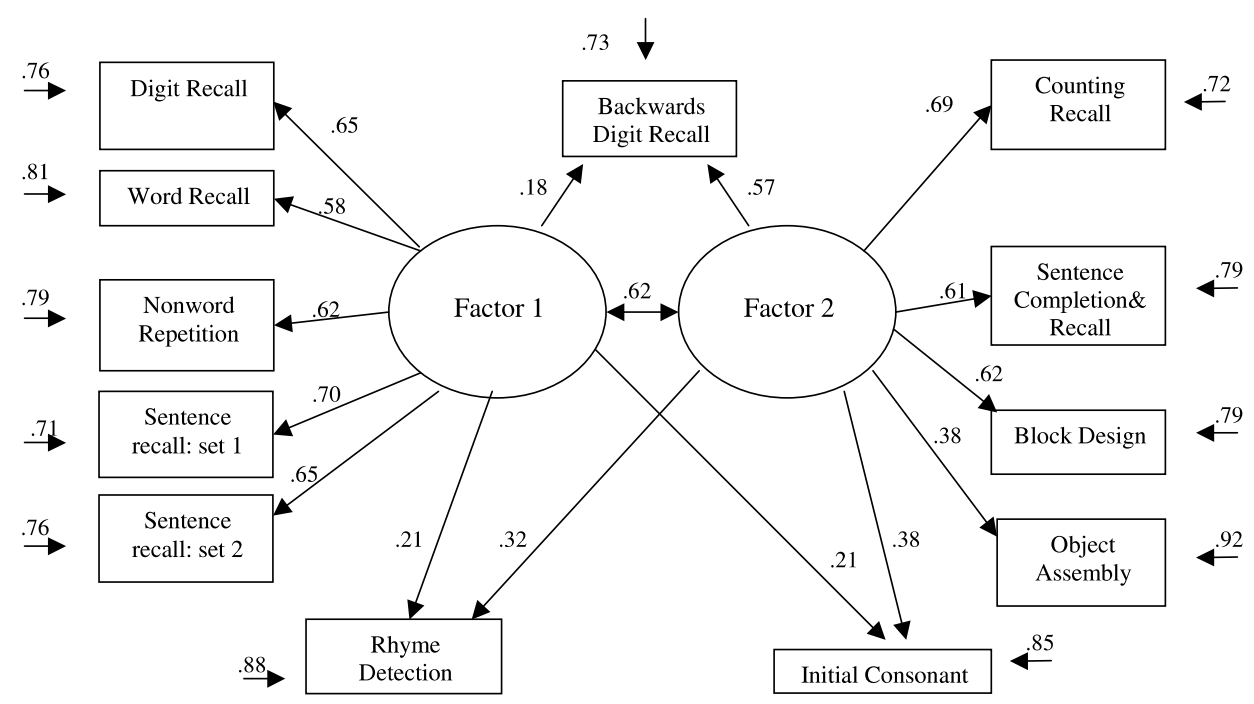

Fig. 1. Path model for two-factor path model based on the factor loadings from the principal components analysis. All factor loadings are significant at the $p<.05$ level.

for the three complex memory span measures were split across the two factors, and the phonological awareness measures were associated with the more general factor rather than with the phonological memory factor. No prior theoretical account is consistent with either of these features of the model. To test whether the data could be better characterised by coherent models generated on the basis of prior theory and data, a series of further models were compared with this initial two-factor solution.

\section{Model 2}

Model 2 tested a unitary account of working memory (e.g., Kail, 2002), in which measures of complex memory span, phonological short-term memory, and sentence repetition were linked to a single factor (Factor 1). Factor 2 corresponded to phonological awareness, indexed by the rhyme detection and initial consonant detection tasks. Factor 3 corresponded to nonverbal ability (block design and object assembly). The model solution is summarised in Fig. 2, and the fit statistics are summarised in Table 4. This model did not provide a satisfactory fit of the data: the $\chi^{2}$ value $(p<.001)$ was greater than that obtained for Model 1, all fit indices were less than .90 , and the RMSEA value exceeded .08.

\section{Model 3}

Model 3 is based on the revised working memory model of Baddeley (2000). It consists of separate factors corresponding to the phonological loop (the three phonological short-term memory measures), the central executive (the three complex span measures), the episodic buffer (the two sentence repetition tasks), phonological 


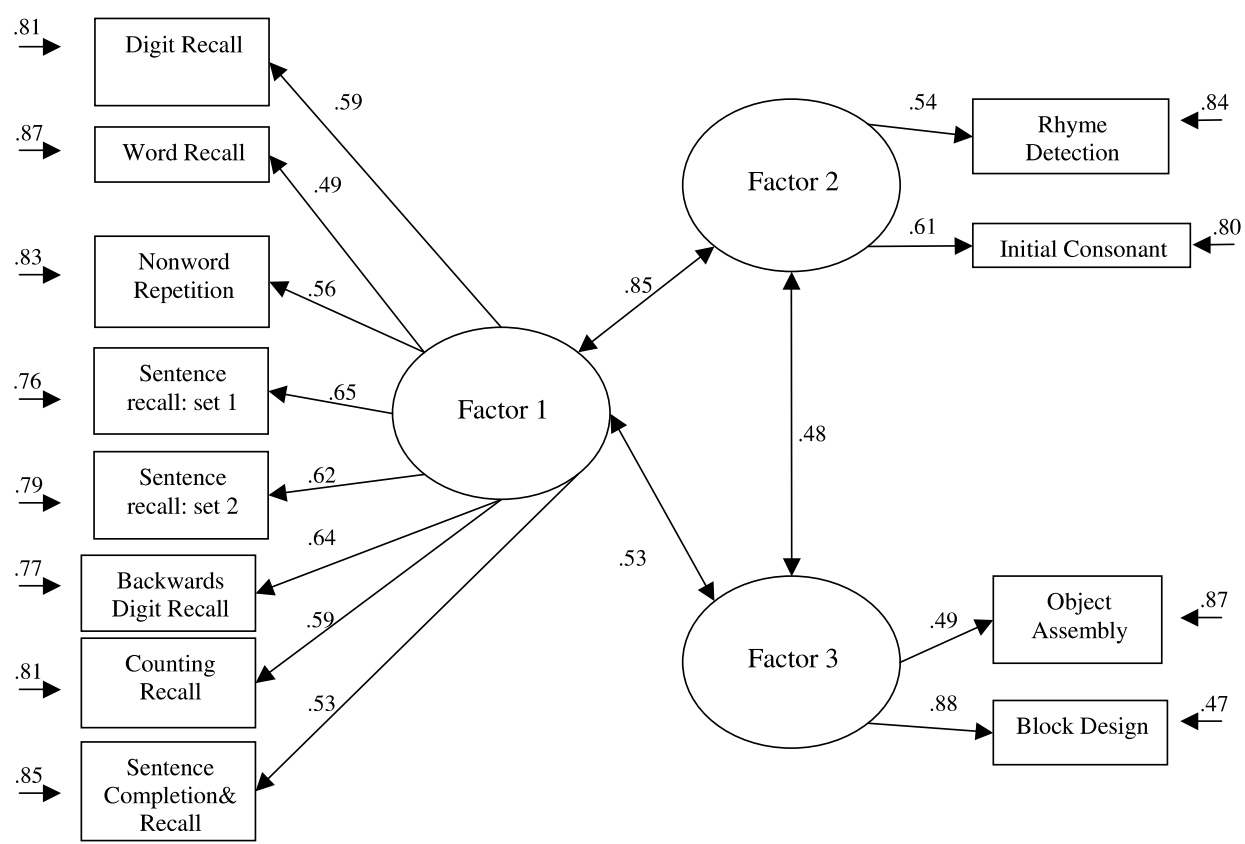

Fig. 2. Path model for three-factor model based on a generic memory component, phonological skills, and nonverbal intelligence. All factor loadings are significant at the $p<.05$ level.

awareness (two tasks), and nonverbal ability (two tasks). The model solution is summarised in Fig. 3, and the model statistics are given in Table 4. This model provides a better fit to the data than either Model 1 or 2 . The $\chi^{2}$ value is considerably lower (although $p<.001$ ), all fit indices are .94 or above, and $R M S E A=.05$, indicating a good-fitting model.

Although this five-factor model provides a good account of the data, some of the correlations between pairs of factors are very high. Factor 4 (sentence recall) is highly correlated with both Factor 1 (complex memory span; .65) and Factor 2 (phonological short-term memory; .77). Factor 5 (phonological awareness) is also highly associated with Factors $1(.88)$ and 2 (.60). Two further four-factor models were therefore tested to determine whether the model fit is comparable when pairs of factors that are highly correlated within Model 3 are collapsed into a single factor. If the simplified models provide accounts of the data that are as satisfactory as Model 3 , they should be favored on grounds of parsimony.

\section{Model $4 a$}

In this model, the sentence recall factor in Model 3 (Factor 4) is eliminated, and the sentence recall measures are associated directly with both Factor 1 (complex memory) and Factor 2 (short-term memory). Phonological awareness and nonverbal skills remain as separate factors. The model solution is summarised in Fig. 4A. This 


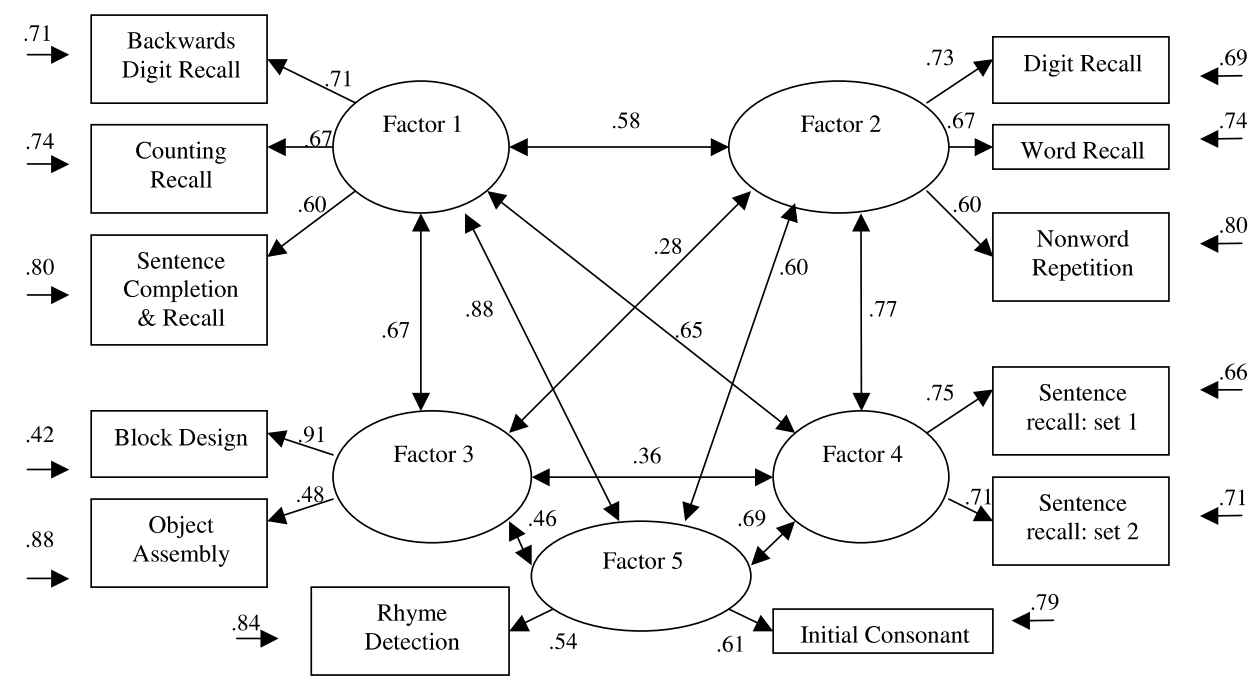

Fig. 3. Path model for three-factor model based on the theoretical distinction between working memory and short-term memory and a separate factor for nonverbal intelligence. All factor loadings are significant at the $p<.05$ level.

model does not provide a better fit to the data than Model 3. The $\chi^{2}$ value is higher; however, all fit indices are above .90 , and $R M S E A=.06$.

\section{Model $4 b$}

In Model 4b, the phonological awareness factor (Factor 5) from Model 3 is eliminated, and the awareness measures are linked directly with both Factor 1 (complex memory) and Factor 2 (short-term memory). Sentence recall and nonverbal measures are distinct factors in the model. The model solution is summarised in Fig. 4B and provides a better fit to the data than Model 4a. The $\chi^{2}$ value is considerably lower, all fit indices are above .90 , and $R M S E A=.06$.

\section{Model comparison}

A series of $\chi^{2}$ difference tests were performed to compare the fit of each of model tested on the data with Model 3, as this model provided the lowest $\chi^{2}$ value and highly satisfactory fit indices. Model 3 was found to provide a significantly better account of the data than each of the other models ( $p<.01$ in all cases): comparison with Model 1, $\Delta \chi^{2}=107.43, d f=6$; comparison with Model 2, $\Delta \chi^{2}=247.71$, $d f=7$; comparison with Model $4 \mathrm{a}, \Delta \chi^{2}=35.04, d f=2$; and, comparison with Model $4 \mathrm{~b}, \Delta \chi^{2}=12.38, d f=2$. The five-factor model consisting of separate factors corresponding to the central executive, episodic buffer, and phonological loop components of working memory plus distinct phonological awareness and nonverbal ability therefore provides the best account of these data. 


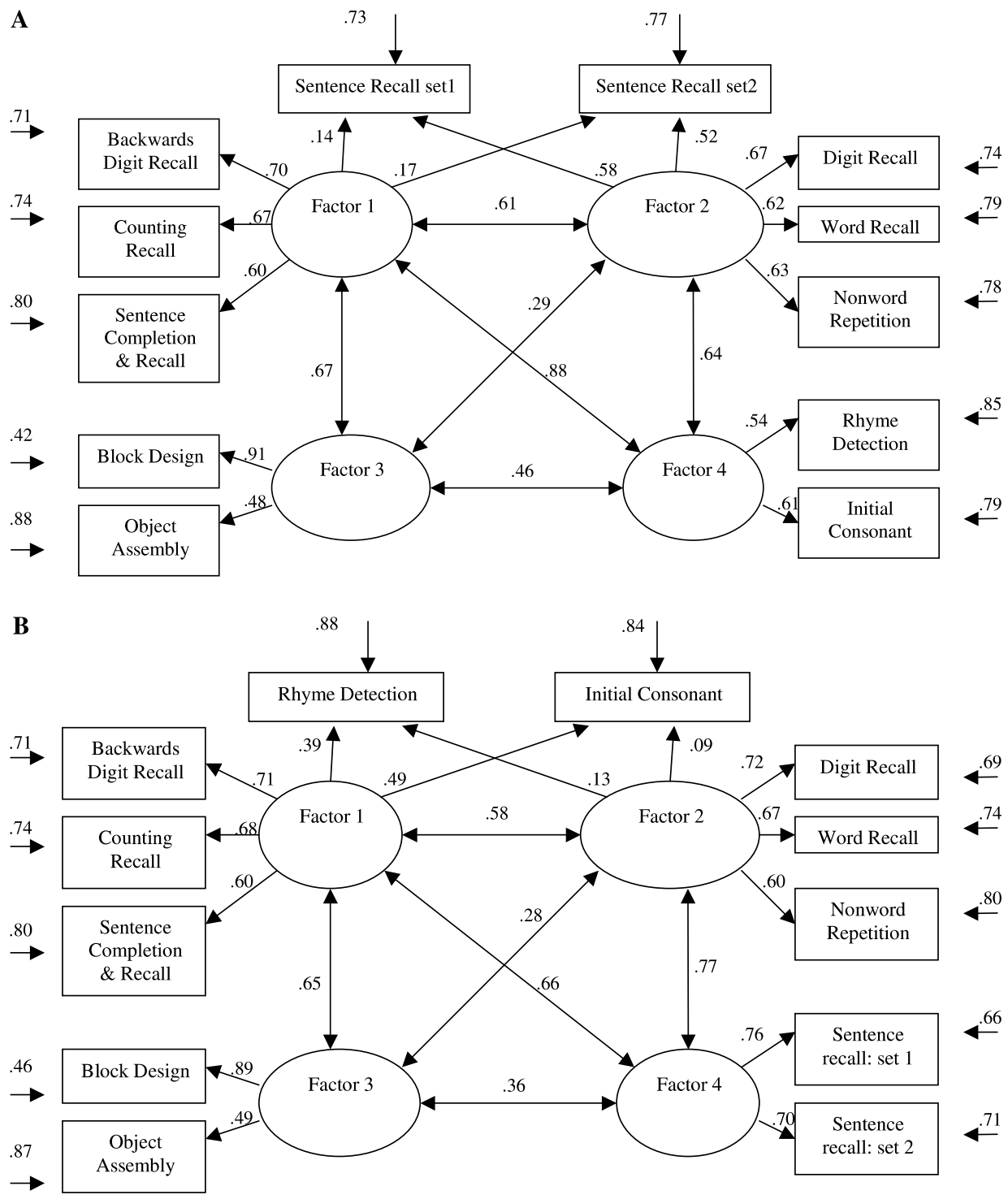

Fig. 4. Path model for five-factor model based on the Baddeley (2000) working memory model. All factor loadings are significant at the $p<.05$ level.

\section{Discussion}

The results from this study indicate that a modular structure that includes an episodic buffer distinct from both the central executive and the phonological loop (Baddeley, 2000) is in place in 4- to 6-year-old children starting school. The children's abilities to repeat meaningful sentences were separable from their capacities both to 
repeat unrelated sequences of verbal items and to engage in more complex tasks that tax both processing and storage skills. Although representing a distinct factor, sentence repetition ability was nonetheless highly associated with both the phonological loop (see Willis \& Gathercole, 2000) and central executive factors. This pattern of findings is consistent with the view that sentence repetition taps the episodic buffer (e.g., Baddeley \& Wilson, 2002), and that the buffer integrates representations from working memory, long-term memory, and language processing and long-term memory systems.

An alternative account of these findings should also be considered. On the basis of neuropsychological evidence, Martin and colleagues have argued for the existence of parallel phonological and semantic short-term memory systems, both of which contribute to tasks such as sentence repetition that require verbatim recall of meaningful information (Hanten \& Martin, 2000; Martin et al., 1999). One possibility is therefore that the latent construct associated with sentence repetition is not the episodic buffer, but is the semantic short-term memory that preserves conceptual representations of the sentence material. The present data are not capable of distinguishing between these theoretical accounts. The episodic buffer account does, however, provide a more complete explanation for how different representations (phonological and semantic) are combined to support the repetition of sentences, within the medium of the episodic buffer. In contrast, the Martin model in its present form does not provide a processing account of how the two different types of temporary representation may be combined.

The close link between the central executive and the phonological loop is also worthy of note, and is consistent with other recent findings both in children and in adults (Engle et al., 1999b; Gathercole \& Pickering, 2000; Gathercole et al., 2003). The strength of this association may reflect in part at least the dependence of verbal complex span tasks on the phonological loop for storage (Baddeley \& Logie, 1999; Duff \& Logie, 2001), which may contribute to the relatively high correlation between the central executive and phonological loop factors. Although the present study employed only verbally based assessments of working memory, other findings indicate that verbal and spatial complex span tasks tap more or less independent factors, suggesting that there may be a domain-specific differentiation of the central executive (Jarvis \& Gathercole, 2003; Shah \& Miyake, 1996). Consistent with this view, nonverbal ability was found to be relatively distinct from the central executive factor identified in these data. Within the verbal domain, however, the present data fit well with the key assumption of the working memory that the central executive plays a crucial role in coordinating the flow of information through the working memory system model (e.g., Baddeley, 2000; Baddeley \& Hitch, 1974), and also with other models that distinguish short-term and working memory (e.g., Cowan, 1995; Engle et al., 1999a).

A further important finding is that in this large sample of young children tested in the first 6 months of school before receiving extensive literacy training, awareness of phonological structure was found to be distinguishable from (although correlated with) the phonological loop. This finding is consistent other recent evidence for separable phonological abilities (e.g., Hecht et al., 2001), but conflicts with other 
findings that a single phonological construct underpins phonological short-term memory and phonological awareness (e.g., Passolunghi \& Siegel, 2001; Wagner et al., 1993). The present results may be a consequence of the young age and hence underdeveloped reading abilities of the children participating in the present study. Early phonological awareness and short-term memory skills may be relatively distinct in young children, but converge over the early school years as a consequence of their joint contributions to literacy development, which in itself appears to promote segmental analysis skills directly (Morais, Alegria, \& Content, 1987). It may also be the case that the relative independence of the phonological awareness and phonological loop factors in this study arises from the choice of picture-based phonological comparison tasks. These are likely to make fewer (although nonetheless significant) demands on phonological memory support than tasks involving spoken inputs that provide no opportunity for the child to regenerate decayed temporary phonological representations, and may therefore have contributed the relative independency of the memory and awareness measures.

This distinction between phonological short-term memory capacity and phonological awareness in children starting formal education established in the present study may provide a useful framework for illuminating the nature of the literacy acquisition process. It raises the possibility that the two phonological skills make separable contributions to success in the earliest stages of reading development. More specifically, it has been suggested that phonological short-term memory may play a role in learning letter-sound correspondences and in storing generated phonological sequences prior to blending and output during phonological recoding (e.g., Gathercole \& Baddeley, 1993). Phonological awareness, in contrast, may be crucial in segmenting phonological representations of words to be spelled (see Goswami \& Bryant, 1990, for a review). This view that the two phonological skills can make separable contributions to reading is supported by previous research (e.g., Wagner et al., 1994).

In summary, the present study has identified a complex structural organisation to working memory and related cognitive abilities in children in their first year of school. The data are consistent with a multicomponent working memory system consisting of a central executive, phonological loop, and episodic buffer with close connections with a separable phonological awareness construct. This multicomponent model provides a useful framework within which to understand subsequent academic development.

\section{Acknowledgments}

This research was supported by a cooperative grant (G0000257) awarded by the Medical Research Council of Great Britain to Susan Gathercole, Catherine Willis, and Anne-Marie Adams. The authors thank Belinda Moore, Annie Crowley, Michelle Davies, Rachel Eaglen, Manon Jones, Emily Lamont, and Carol Sadler for their assistance in data collection. We also thank Nelson Cowan and an anonymous reviewer for helpful comments on an earlier draft. 


\section{References}

Baddeley, A. D. (1986). Working memory. Oxford: Oxford Univ. Press.

Baddeley, A. D. (1996). Exploring the central executive. Quarterly Journal of Experimental Psychology A, 49, 5-28.

Baddeley, A. D. (1998). The central executive: A concept and some misconceptions. Journal of the International Neuropsychological Society, 4, 523-526.

Baddeley, A. D. (2000). The episodic buffer: A new component of working memory? Trends in Cognitive Sciences, 4, 417-422.

Baddeley, A. D., Della Sala, S., Gray, C., Papagno, C., \& Spinnler, H. (1997). Testing central executive functioning with a pencil-and-paper test. In P. Rabbitt (Ed.), Methodology of frontal and executive function (pp. 61-80). Hove: Psychology Press.

Baddeley, A. D., Emslie, H., Kolodny, J., \& Duncan, J. (1998a). Random generation and the executive control of working memory. Quarterly Journal of Experimental Psychology A, 51, 819-852.

Baddeley, A. D., Gathercole, S. E., \& Papagno, C. (1998b). The phonological loop as a language learning device. Psychological Review, 105, 158-173.

Baddeley, A. D, \& Hitch, G. (1974). Working memory. In G. Bower (Ed.), The psychology of learning and motivation (Vol. 8, pp. 47-90). New York: Academic Press.

Baddeley, A. D., \& Lieberman, K. (1980). Spatial working memory. In R. S. Nickerson (Ed.), Attention and performance VIII (pp. 521-539). Hillsdale, NJ: Lawrence Erlbaum Associates Inc.

Baddeley, A. D., \& Logie, R. H. (1999). The multiple-component model. In A. Miyake \& P. Shah (Eds.), Models of working memory: Mechanisms of active maintenance and executive control (pp. 28-61). New York: Cambridge Univ. Press.

Baddeley, A. D., Wilson, B. A., (2002). Prose recall and amnesia: Implications for the structure of working memory. Neuropsychologia, 40, 1737-1743.

Bentler, P. M. (1990). Comparative fit indexes in structural models. Psychological Bulletin, 107, 238-246.

Bentler, P. M. (2001). EQS structural equation modelling software (version 6.0) [Computer software]. USA: mvsoft.

Bentler, P. M., \& Bonett, D. G. (1980). Significance tests and goodness of fit in the analysis of covariance structures. Psychological Bulletin, 88, 588-606.

Bentler, P. M., \& Wu, E. J. C. (1995). EQS for Macintosh user's guide. Encino, CA: Multivariate Software Inc.

Bishop, D. (1982). Test for reception of grammar. United Kingdom: Medical Research Council.

Bollen, K. A. (1989). Structural equations with latent variables. New York: Wiley.

Bowey, J. A. (1996). On the association between phonological memory and receptive vocabulary in fiveyear-olds. Journal of Experimental Child Psychology, 63, 44-78.

Bradley, L., \& Bryant, P. E. (1983). Categorizing sound and learning to read-A causal connection. Nature, 301, 419-421.

Bradley, L., \& Bryant, P. E. (1985). Rhyme and reason in reading and spelling (I.A.R.L.D. Monographs No.1). Ann Arbor: Univ. of Michigan Press.

Bull, R., \& Scerif, G. (2001). Executive functioning as a predictor of children's mathematics ability: Inhibition, task switching, and working memory. Developmental Neuropsychology, 19, 273-293.

Byrne, B., \& Fielding-Barnsley, R. (1993). Recognition of phoneme invariance by beginning readers: Confounding effects of global similarity. Reading and Writing, 6, 315-324.

Conway, A. R. A., Cowan, N., Bunting, M. F., Therriault, D. J., \& Minkoff, S. R. B. (2002). A latent variable analysis of working memory capacity, short-term memory capacity, processing speed, and general fluid intelligence. Intelligence, 30, 163-183.

Cowan, N. (1988). Evolving conceptions of memory storage, selective attention, and their mutual constraints within the human information processing system. Psychological Bulletin, 104, 163-191.

Cowan, N. (1995). Attention and memory: An integrated framework. Oxford: Oxford Univ. Press.

Cowan, N. (1997). The development of working memory. In N. Cowan (Ed.), The development of memory in childhood (pp. 163-200). Hove: Psychology Press.

Daneman, M., \& Carpenter, P. A. (1980). Individual differences in working memory and reading. Journal of Verbal Learning and Verbal Behavior, 19, 450-466. 
Daneman, M., \& Carpenter, P. A. (1983). Individual differences in integrating information between and within sentences. Journal of Experimental Psychology: Learning, Memory and Cognition, 9, 561-584.

De Jong, P. F. (1998). Working memory deficits of reading disabled children. Journal of Experimental Child Psychology, 70, 75-96.

De Jong, P. F., Seveke, M. J., \& van Veen, M. (2000). Phonological sensitivity and the acquisition of new words in children. Journal of Experimental Child Psychology, 76, 275-301.

Della Sala, S., Gray, C., Baddeley, A. D., Allamano, M., \& Wilson, L. (1999). Pattern span: A tool for unwelding visuo-spatial memory. Neuropsychologia, 37, 1189-1199.

Duff, S. C., \& Logie, R. H. (2001). Processing and storage in working memory span. Quarterly Journal of Experimental Psychology A, 54, 31-48.

Dufva, M., Niemi, P., \& Voeten, M. J. M. (2001). The role of phonological memory, word recognition, and comprehension skills in reading development: From preschool to grade 2. Reading and Writing: An Interdisciplinary Journal, 14, 91-117.

Engle, R. W., Kane, M. J., \& Tuholski, S. W. (1999a). Individual differences in working memory capacity and what they tell us about controlled attention, general fluid intelligence, and functions of the prefrontal cortex. In A. Miyake \& P. Shah (Eds.), Models of working memory: Mechanisms of active maintenance and executive control (pp. 102-134). New York: Cambridge Univ. Press.

Engle, R. W., Tuholski, S. W., Laughlin, J. E., \& Conway, A. R. A. (1999b). Working memory, short-term memory, and general fluid intelligence: A latent variable approach. Journal of Experimental Psychology: General, 125, 309-331.

Garlock, V. M., Walley, A. C., \& Metsala, J. L. (2001). Age-of-acquisition, word frequency and neighbourhood density effects on the development of spoken word recognition and phoneme awareness. Journal of Memory and Language, 45, 468-492.

Gathercole, S., \& Baddeley, A. (1993). Working memory and language. Hove: LEA.

Gathercole, S. E., \& Baddeley, A. D. (1996). The children's test of nonword repetition. London: Psychological Corp.

Gathercole, S. E., Brown, L., \& Pickering, S. J. (2003). Working memory assessments at school entry as longitudinal predictors of national curriculum attainment levels. Educational and Child Psychology, 20, $109-122$.

Gathercole, S. E., \& Pickering, S. J. (2000). Assessment of working memory in six- and seven-year old children. Journal of Educational Psychology, 92, 377-390.

Gathercole, S. E., Pickering, S. J., Ambridge, B., Wearing, H. (in press). The structure of working memory from 4 to 15 years. Developmental Psychology.

Gathercole, S. E., Willis, C., \& Baddeley, A. D. (1991). Differentiating phonological memory and awareness of rhyme: Reading and vocabulary development in children. British Journal of Psychology, $82,387-406$.

Goswami, U., \& Bryant, P. (1990). Phonological skills and learning to read. Hillsdale, NJ: Erlbaum.

Griffiths, Y. M., \& Snowling, M. J. (2002). Predictors of exception word and nonword reading in dyslexic children: The severity hypothesis. Journal of Educational Psychology, 94, 34-43.

Hanten, G., \& Martin, R. (2000). Contributions of phonological and semantic short-term memory to sentence processing: Evidence from two cases of closed head injury in children. Journal of Memory and Language, 43, 335-361.

Hecht, S. A., Torgesen, J. K., Wagner, R. K., \& Rashotte, C. A. (2001). The relations between phonological processing abilities and emerging individual differences in mathematical computation skills: A longitudinal study from second to fifth grade. Journal of Experimental Child Psychology, 79, 192-227.

Hulme, C., \& Snowling, M. J. (1992). Deficits in output phonology: An explanation of reading failure? Cognitive Neuropsychology, 9, 47-72.

Jaccard, J., \& Wan, C. K. (1996). LISREL approaches to interaction effects in multiple regression. Thousand Oaks, CA: Sage.

Jarvis, H. L., \& Gathercole, S. E. (2003). Verbal and non-verbal working memory and achievements on national curriculum tests at 11 and 14 years of age. Educational and Child Psychology, 20, 123-140.

Just, M. A., \& Carpenter, P. A. (1992). A capacity theory of comprehension: Individual differences in working memory. Psychological Review, 99, 122-149. 
Kail, R. (2002). Developmental change in proactive interference. Child Development, 73, $1703-1714$.

Kail, R., \& Hall, L. K. (2001). Distinguishing short-term memory from working memory. Memory \& Cognition, 29, 1-9.

Kail, R., \& Park, Y. (1994). Processing time, articulation time, and memory span. Journal of Experimental Child Psychology, 57, 281-291.

Kirtley, C., Bryant, P., MacLean, M., \& Bradley, L. (1989). Rhyme, rime, and the onset of reading. Journal of Experimental Child Psychology, 48, 224-245.

Kline, R. B. (1998). Principles and practice of structural equation modelling. New York: Guilford.

Kyllonen, P. C., \& Christal, R. E. (1990). Reasoning ability is (little more than) working-memory capacity?!. Intelligence, 14, 389-433.

Leather, C. V., \& Henry, L. A. (1994). Working memory span and phonological awareness tasks as predictors of early reading ability. Journal of Experimental Child Psychology, 58, 88-111.

Liberman, I. Y., Shankweiler, D., Liberman, A. M., Fowler, C., \& Fischer, F. (1977). Phonetic segmentation and recoding in the beginning reader. In A. S. Reberm \& D. L. Scarborough (Eds.), Toward a psychology of reading (pp. 207-225). Hillsdale, NJ: Erlbaum.

MacDonald, M. C., Just, M. A., \& Carpenter, P. A. (1992). Working memory constraints on the processing of syntactic ambiguity. Cognitive Psychology, 24, 56-98.

Mann, V. A., \& Liberman, I. Y. (1984). Phonological awareness and verbal short term memory: Can they presage early reading problems? Journal of Learning Disabilities, 17, 592-599.

Martin, R., Lesch, M., \& Bartha, M. (1999). Independence of input and output phonology in word processing and short-term memory. Journal of Memory and Language, 41, 3-29.

Mayringer, H., \& Wimmer, H. (2000). Pseudoname learning by German-speaking children with dyslexia: Evidence for a phonological learning deficit. Journal of Experimental Child Psychology, 75, 116-133.

McCarthy, R. A., \& Warrington, E. K. (1987). The double dissociation of short-term memory for lists and sentences. Brain, 110, 1545-1563.

McDonald, R. P., \& Ho, R. M. (2002). Principles and practice in reporting structural equation analyses. Psychological Methods, 7, 64-82.

Metsala, J. L. (1999). The development of phonemic awareness in reading disabled children. Applied Psycholinguistics, 20, 149-158.

Miyake, A., Emerson, M. J., \& Friedman, N. P. (2000). Assessment of executive functions in clinical settings: Problems and recommendations. Seminars in Speech and Language, 21, 169-183.

Morais, J., Alegria, J., \& Content, A. (1987). The relationships between segmental analysis and alphabetic literacy-An interactive view. Cahiers de Psychologie Cognitive, 7, 415-438.

Morais, J., Content, A., Bertelson, P., Cary, L., \& Kolinksy, R. (1988). Is there a critical period for the acquisition of segmental analysis? Cognitive Neuropsychology, 5, 347-352.

Muter, V., Hulme, C., \& Snowling, M. J. (1997). The phonological abilities test. London: Psychological Corp.

Muter, V., \& Snowling, M. J. (1998). Concurrent and longitudinal predictors of reading: The role of mentalinguistic and short-term memory skills. Reading Research Quarterly, 33, 320-337.

Nation, K., Adams, J. W., Bowyer-Crane, C. A., \& Snowling, M. J. (1999). Working memory deficits in poor comprehenders reflect underlying language impairments. Journal of Experimental Child Psychology, 73, 139-158.

Oakhill, J., \& Kyle, F. (2000). The relation between phonological awareness and working memory. Journal of Experimental Child Psychology, 75, 152-164.

Passolunghi, M. C., \& Siegel, L. S. (2001). Short-term memory, working memory, and inhibitory control in children with difficulties in arithmetic problem solving. Journal of Experimental Child Psychology, $80,44-57$.

Perin, D. (1983). Phonemic segmentation and spelling. British Journal of Psychology, 74, 129-144.

Pickering, S. J., \& Gathercole, S. E. (2001). Working memory test battery for children. London: Psychological Corp.

Potter, M., \& Lombardi, L. (1990). Regeneration in the short-term recall of sentences. Journal of Memory and Language, 29, 633-654.

Seigneuric, A., Ehrlich, M. F., Oakhill, J. V., \& Yuill, N. M. (2000). Working memory resources and children's reading comprehension. Reading and Writing, 13, 81-103. 
Shah, P., \& Miyake, A. (1996). The separability of working memory resources for spatial thinking and language processing: An individual differences approach. Journal of Experimental Psychology: General, $125,4-27$.

Siegal, L. S., \& Linder, B. A. (1984). Short-term memory processes in children with reading and arithmetic learning disabilities. Developmental Psychology, 20, 200-207.

Siegal, L. S., \& Ryan, E. B. (1989). The development of working memory in normally achieving and subtypes of learning disabled children. Child Development, 60, 973-980.

Stanovich, K. E., Cunningham, A. E., \& Freeman, D. J. (1984). Intelligence, cognitive skills and early reading progress. Reading Research Quarterly, 19, 278-303.

Swanson, H. L. (1994). Short-term memory and working memory: Do both contribute to our understanding of academic achievement in children and adults with learning disabilities? Journal of Learning Disabilities, 27, 34-50.

Towse, J. N., Hitch, G. J., \& Hutton, U. (1998). A reevaluation of working memory capacity in children. Journal of Memory and Language, 39, 195-217.

Treiman, R., \& Baron, J. (1981). Segmental analysis: Development and relation to reading ability. In G. C. MacKinnon \& T. G. Waller (Eds.), Reading research: Advances in theory and practice (Vol. III, pp. 159-197). New York: Academic Press.

Vallar, G., \& Baddeley, A. D. (1984). Phonological short-term store, phonological processing and sentence comprehension: A neuropsychological case study. Cognitive Neuropsychology, 1, 121-141.

Wagner, R. K., \& Torgesen, J. (1987). The nature of phonological processing and its causal role in the acquisition of reading skills. Psychological Bulletin, 101, 192-212.

Wagner, R. K., Torgesen, J. K., Laughon, P., Simmons, K., \& Rashotte, C. A. (1993). Development of young readers' phonological processing abilities. Journal of Educational Psychology, 85, 83-103.

Wagner, R. K., Torgesen, J. K., \& Rashotte, C. (1994). Development of reading-related phonological processing abilities: New evidence of bi-directional causality from a latent variable longitudinal study. Journal of Educational Psychology, 85, 83-103.

Wagner, R. K., Torgesen, J. K., Rashotte, C. A., Hecht, S. A., Barker, T. A., Burgess, S. R., et al. (1987). Changing relations between phonological processing abilities and word level reading as children develop from beginning to skilled readers: A 5-year longitudinal study. Developmental Psychology, 33, 468-479.

Wechsler, D. (1990). Wechsler Pre-School and Primary Scale of Intelligence-Revised UK Edition. London: Psychological Corp.

Willis, C. S., \& Gathercole, S. E. (2000). Phonological short-term memory contributions to sentence processing in young children. Memory, 9, 349-363.

Windfuhr, K. L., \& Snowling, M. J. (2001). The relationship between paired associate learning and phonological skills in normally developing readers. Journal of Experimental Child Psychology, 80, 160 173. 